\title{
The disassembly and re-purposing of unwanted consumer electronics: low- cost tools for optics outreach
}

Laura Andre, Timothy Jones

Laura B. Andre, Timothy Jones, "The disassembly and re-purposing of unwanted consumer electronics: low-cost tools for optics outreach," Proc. SPIE 11143, Fifteenth Conference on Education and Training in Optics and Photonics: ETOP 2019, 111431E (2 July 2019); doi: 10.1117/12.2523621 Photonics: ETOP 2019, 2019, Quebec City, Quebec, Canada 


\title{
The disassembly and re-purposing of unwanted consumer electronics: low-cost tools for optics outreach
}

\author{
Laura B. Andre*a ${ }^{*}$ Timothy Jones ${ }^{\mathrm{b}}$ \\ ${ }^{a}$ Department of Electrical and Computer Engineering, University of Michigan, 1301 Beal Ave., Ann \\ Arbor, MI, USA 48109; ${ }^{\mathrm{b} A n n}$ Arbor Section of the Optical Society, Ann Arbor, MI, USA 48105
}

\begin{abstract}
Community outreach events conducted by collaborating optical societies in Southeast Michigan shaped our perception of local science education needs and caused us to explore whether discarded consumer electronics might be utilized for low-cost and hands-on STEM activities. We found that point-and-shoot cameras are widely available and excellent sources for optical and electromechanical components. Moreover, the process of disassembly along with the exploration and use of recovered components was a flexible platform for learning activities. In this exploratory case study, elementary school students disassembled cameras, harvested lenses, motors, and other functional mechanisms then reused these components to build something new. The activity encouraged a process of inquiry, independent exploration and tinkering, and deserves further investigation as an educational tool for the introduction of STEM topics. Our approach, safety precautions, and tips for disassembling cameras are discussed.
\end{abstract}

Keywords: Outreach, pre-college, re-purposing, recycling, e-cycling, reverse engineering, cameras, electronics

\section{INTRODUCTION}

Concerns about K-12 science illiteracy has caused many professional technical and scientific organizations to expand pre-college educational programming and support for outreach activities. The declaration of 2015 as the International Year of Light (IYL) by the United Nations and other initiatives have been created to address broader issues regarding public awareness and perception of the benefits of science. As part of this call to action, the Optics Society at the University of Michigan (OSUM) and the Ann Arbor Section of the Optical Society (AAOSA) conducted engagements at local schools as well at a variety of community events and festivals. ${ }^{1}$ Here we describe our attempt to respond to local needs and create an educational activity that addresses teachers' cost concerns and technical needs and also is capable of sparking curiosity about science and technology.

The successes and struggles of this outreach yielded valuable insights into some of the challenges faced in acting on these initiatives. In particular, the difficulties encountered by pre-college science educators in Michigan became readily apparent. Hands-on activities require a disproportionate investment in advance planning, materials, and classroom time compared to other methods of instruction. There is also a hesitation that worthwhile science projects may be outside of one's technical expertise. Moreover, hands-on activities, or at least having one per student, are simply too costly for many schools and programs.

Other concerns have arisen regarding the effectiveness of public outreach activities and their significance to future engineers and scientists. Optical demonstrations and short hands-on exercises at community events and science-related festivals may only be reaching a well-educated crowd that is already inclined towards science. A study in the United Kingdom demonstrated that community and science festivals do not adequately reach a socio-economically diverse audience that is representative of the general public. ${ }^{2}$ We observed similar concerns regarding exposure to science and technology among visitors during outreach activities at festivals in Michigan. There is also evidence that pre-collegiate STEM exposure has no effect on the success of undergraduate engineering students who were exposed to pre-college engineering outreach programs versus those who were not. ${ }^{3}$ Exposure to formal technology and pre-engineering classes were correlated to high self-efficacy scores, a predictor of future success in undergraduate engineering. However, there was no measurable effect from multi-day engineering programs, school-related extracurricular engineering programs, and single-day workshops or field trips.

*lbandre@umich.edu; phone: 1734 764-9578; https://opticsumich.com

Fifteenth Conference on Education and Training in Optics and Photonics: ETOP 2019, edited by

Anne-Sophie Poulin-Girard, Joseph A. Shaw, Proc. of SPIE Vol. 11143, 111431E · (C) 2019

SPIE, ICO, IEEE, OSA · CCC code: 0277-786X/19/\$18 · doi: 10.1117/12.2523621 
Many of our society members recall personal experiences with a hobby such as robotics, electronics, model building, or programming. These hobbies are characterized by hands-on experiences, self-motivated learning, real-world applications, immediate feedback, and problem-based projects. The skills that these types of hobbies build are strongly associated with success and persistence in engineering students. ${ }^{3}$ For pre-college students, an early positive experience with science and technology should associate with positive attitudes toward STEM topics and better long-term outcomes. The fact that hobbies do not occupy classroom time and often start incidentally adds to their attractiveness as a model for innovative outreach activities. Hobbies require access to resources that many urban school students lack, including components, tools, and social support. Disassembly could mitigate much of the economic burden for both formal classroom and at-home learning activities. Consequently, we explored how to turn an age-old tinkering practice into an outreach project - obtaining free supplies and materials through the deconstruction of a consumer product to harvest parts and components.

While there is a growing body of literature describing hands-on STEM activities for high school and undergraduate engineering students, there is relatively little information regarding the reverse engineering and repurposing of consumer products, like cameras, for early age students. We created and tested a format for the structured disassembly of pointand-shoot cameras by elementary school-age students. The objective was to gain basic insight into the practicality of disassembling consumer electronics, gauge whether the approach might serve as a platform for multiple project activities and observe students' reaction to our program. The project was purely exploratory and was formulated to have three phases: disassembling an item, investigating its components and subsystems, and re-purposing the scrap parts and components to build something new or to demonstrate some aspect of science. We believe the unique combination of these activities can provide young students a safe, hands-on opportunity for exploration and the tools for tinkering with technology while fostering curiosity and motivating learning.

\section{MATERIALS AND METHODS}

Our investigation began with an examination of the safety, practicality, and availability of unwanted consumer electronics for disassembly. A site visit to a certified electronics waste recycler that repairs and resells discarded electronics was particularly helpful. They hold weekly electronics disassembly sessions for school groups and others that have proven to be an extremely popular activity. Next, we hosted a focus group with OSUM volunteers and dissected various recycled consumer electronics to consider issues pertaining to disassembly and to brainstorm project activities that might be possible using the recovered components. Videocassette recorders were of interest as the project focus but were simply too bulky to be practical and lacked optical elements. Portable CD players, cassette tape players, and electronic toys are a safe disassembly activity but contain few recoverable parts other than motors and suffer from availability. We chose to utilize recycled point-and-shoot cameras for this project as they contain a wealth of potentially useful optical and mechanical components and have increased in availability in recent years with the growing popularity of smartphones. In 2014 it was estimated that there were 180 million standalone digital cameras that sit unused in homes $^{4}$ and our local electronics recycler suggests that over 20 million film cameras will be discarded in the US in the coming years. Digital cameras are useful for disassembly; however, they lack the film transport system and other mechanics that make film cameras so favorable for re-purposing projects.

Digital and film point-and-shoot cameras were collected from local resale and thrift stores only if priced at $\$ 5$ or less. Damaged and broken cameras are free and just as useful for our purposes. All batteries were immediately removed, and the cameras were stored to let capacitors discharge as a safety precaution. To fully disassemble a camera, the only tool necessary is a Phillips \#0001 precision screwdriver. Safety glasses are required as small parts occasionally break off during disassembly. Paper plates and small bags to contain and store parts during the project are helpful. After the camera's housing is removed, a pair of wire cutters can be used to disconnect some of the components - scissors also work since the wires have a relatively narrow gauge. In order to examine the functionality of internal subsystems, we recommend supplying a $3 \mathrm{~V}$ battery pack. The battery pack with wire leads can be used to power some of the internal components visible at this stage. Table 1 below summarizes the materials necessary to complete the disassembly phase of the project. We estimate that a single disassembly kit that would give one student everything they need to take apart a camera could cost as little as $\$ 10$. 
Table 1. Materials and estimated total cost for one camera disassembly kit.

\begin{tabular}{|c|c|c|c|}
\hline Materials & Quantity & Unit Price & Source \\
\hline Camera & 1 & $\sim \$ 5$ & Electronics Recycle Center \\
\hline Safety Glasses & 1 & $\$ 1$ & Home Depot \\
\hline Phillips \#0001 Screwdriver & 1 & $\$ 3$ & Home Depot \\
\hline Wire Cutters (optional) & 1 & $(\$ 6)$ & Home Depot \\
\hline AA Battery Holder with Wire Leads & 1 & $\$ 1$ & DigiKey \\
\hline & Total: & $\$ 10(\$ 16)$ & \\
\hline
\end{tabular}

Our participants consisted of about 30 students from two after school voluntary tutoring and mentoring programs, forming two separate cohorts. The first group consisted of second through eleventh grade students at a church's tutoring program, while the second was fourth and fifth grade students who elected to participate in the project given other activity choices. The total activity time averaged five hours for both cohorts - the first was broken up into two sessions, and the second was scheduled as half-hour sessions held once per week for 10 weeks. Before disassembly, students were asked about their perceptions and knowledge of science and technology. Cameras were distributed one per student and they were instructed to fill out worksheets indicating parts of the camera, functions, and what they thought was inside. Disassembling the cameras was proposed to examine internal components and learn about how the camera operates. We found that camera weight and density were positively correlated to the quality and quantity of useful parts. This allowed us to judge the complexity of a camera and the flexibility to tailor the camera choice to the age or perceived expertise of each student.

Following a commitment from the students to follow safety instructions, safety glasses and screwdrivers were distributed. Several OSUM volunteers, a program mentor, and occasional parents were available to help the students loosen screws, open the camera housing, and observe safety precautions. In the first cohort, several parents also disassembled a camera. Once the housing is removed, we confirmed that after storing the cameras the flash circuit was discharged by repeatedly shorting out the flash capacitors using the insulated screwdriver. All parts were contained on paper plates and saved in Ziploc bags between sessions. With the camera housing removed, examples of the camera subsystems such as the viewfinder and motor-driven lens assembly were exhibited and discussed. Students were challenged to find and remove the subsystems intact from their camera. Many of these systems are simply bolted onto the camera frame, making their intact removal possible. We introduced technical vocabulary as the students continued to extract and identify their parts: LEDs, lenses, motors, gears, etc. The $3 \mathrm{~V}$ battery pack allows the students to power systems and components to discover their function. For example, they could run one or more of the DC motors or light the LEDs by simply touching the bare wire leads to the correct terminals. Students were instructed to observe, ponder, tinker, and test. We also encouraged participants to disassemble a subsystem and then attempt to reassemble it. As reverse engineering some of the subsystems can involve a considerable number of parts, we suggested bagging unrelated parts and working on a clean plate. Even if the item is not able to be perfectly reassembled, the process is still a valuable learning experience for the students.

Session breaks, instructions, and re-purposing activities forced the process of disassembly into short blocks of time. Brief lectures were formulated to present scientific concepts as they related to the camera components students were exploring. After certain components were extracted, students tended to naturally investigate the items. Disassembly was also paused to let students get creative and try to build something new with the recovered parts. Examples of repurposing ideas and construction projects can be found in the following section.

Finally, at the project conclusion, the students were allowed to keep their components, a battery pack, and the projects they constructed. This required that each parent be supplied with a warning notice stating some of the risks involved, particularly with younger siblings ingesting small parts, battery dangers, etc. We believe the take home components are critical to students revisiting their experience, hopefully recalling lesson material, and engaging in self-motivated tinkering. Approximately $70 \%$ of the students elected to take home their components and all chose to keep their individual constructions. A list of all useful subsystems along with a description and possible project activities can be found in Table 2 on the following pages. 
Table 2. List of camera subsystems, descriptions, and project activities.

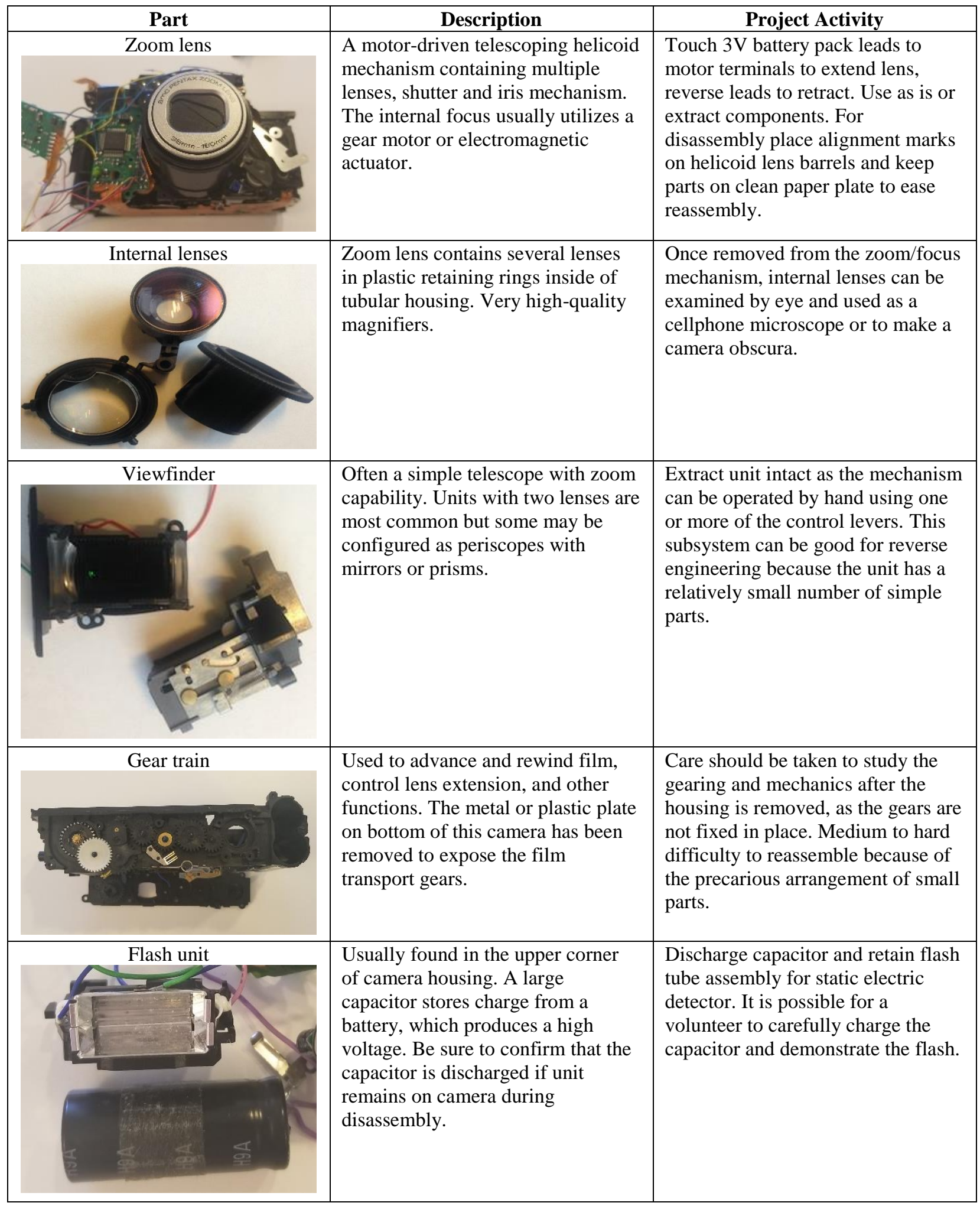


Table 2. (Continued) List of camera subsystems, descriptions, and project activities.

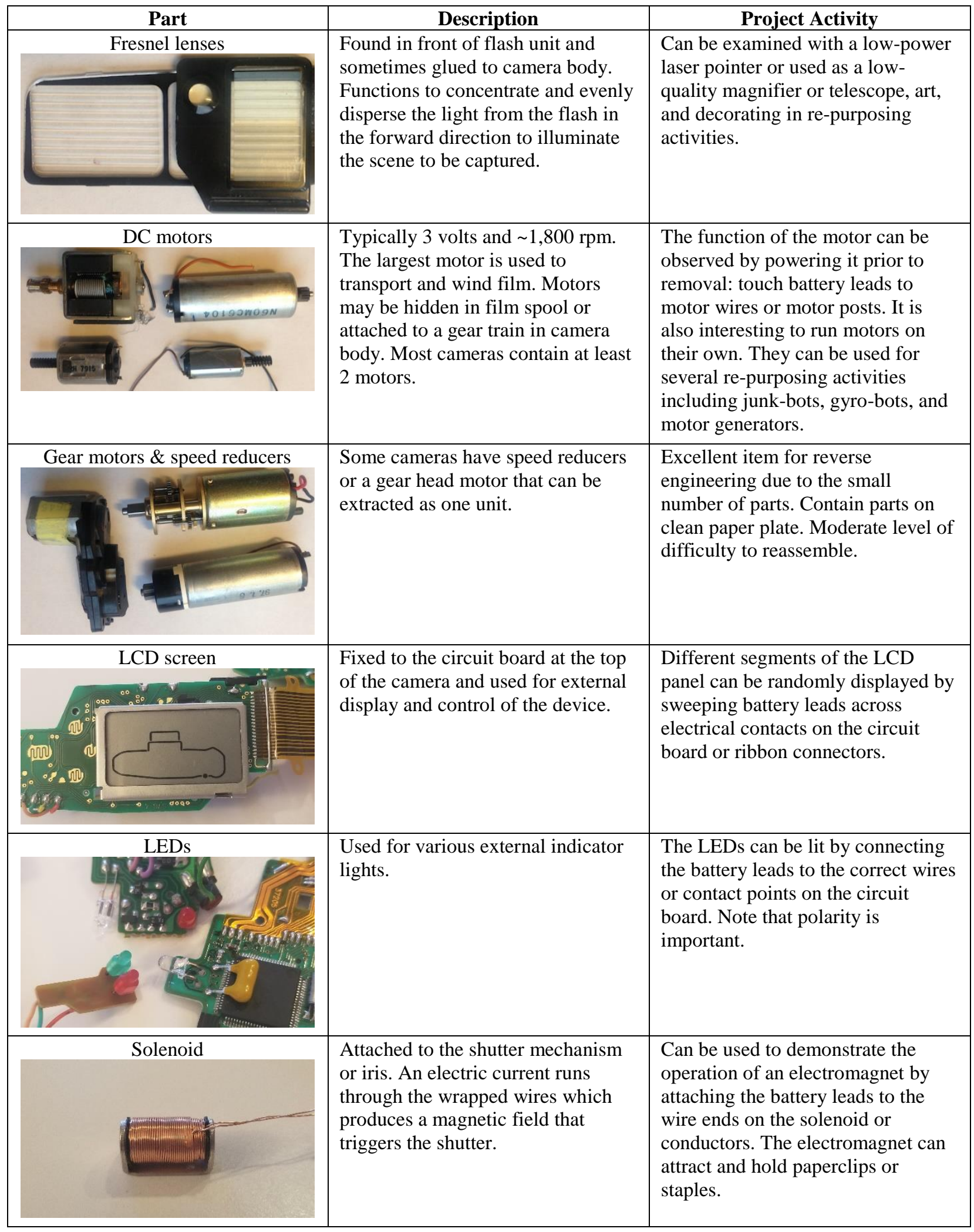


Table 2. (Continued) List of camera subsystems, descriptions, and project activities.

\begin{tabular}{|l|l|l|}
\hline Part & \multicolumn{1}{|c|}{ Description } & \multicolumn{1}{c|}{ Project Activity } \\
\hline Electromagnetic Actuator & $\begin{array}{l}\text { Found inside the telescoping lens } \\
\text { tubes. The electromagnetic actuator } \\
\text { uses a solenoid to adjust the focus } \\
\text { on some cameras. }\end{array}$ & $\begin{array}{l}\text { The focusing mechanism of the lens } \\
\text { can be demonstrated by powering } \\
\text { the solenoid. It is important to } \\
\text { remove actuator with the ribbon } \\
\text { conductors attached. }\end{array}$ \\
\hline
\end{tabular}

\section{RE-PURPOSING AND CONSTRUCTION ACTIVITIES}

Throughout the disassembly phase, we found it useful to intermittently present simple construction projects. After the removal of a subsystem or component and a brief lesson, the students can use what they learned about the functions of each part to build something new. Coming up with reassembly projects with the parts available has proven to be the most challenging part of the project. The brainstorming and creative input from OSUM volunteers during the focus group and throughout the project was extremely helpful in this task. The simplest re-purposing project idea we came up with is using the scrap parts for either art or building small circuit animals by gluing pieces together. This is most suited to a younger age group and was executed well by second grade students. The circuit animals can be taken to the next level of complexity by adding a motor and battery pack to nearly any light household item to create a vibrating creature we're calling a junk-bot. Examples of the circuit animal and a junk-bot can be seen in the picture included in Figure 1.

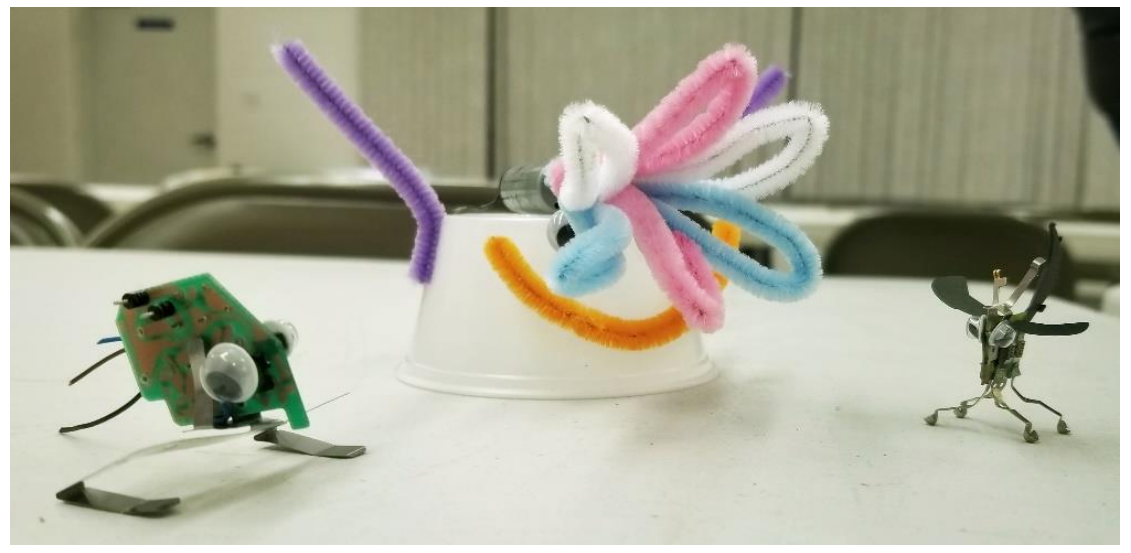

Figure 1. Two circuit animals (left and right) and a vibrating junk-bot (center).

The internal lenses found in a camera's telescoping zoom mechanism are high quality and function well to simply teach the students about lenses. Other than examining the lenses by eye, they can also be used to create a simple microscope by fixing it to a small camera or cellphone using rubber bands. A cellphone microscope as well as an example of a photo taken using this device can be seen in Figure 2. The students enjoyed being able to more closely examine the components from the disassembled cameras and were fascinated by the intricate details of the circuits. 

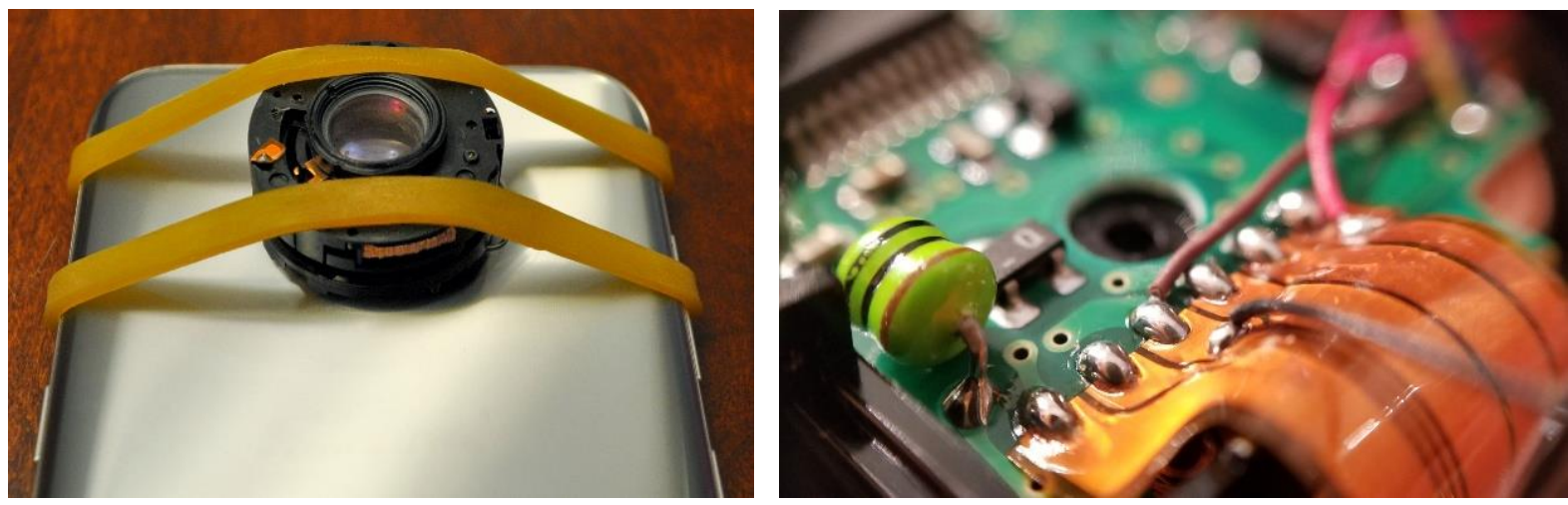

Figure 2. A cellphone microscope made from an internal camera lens (left) and an example of an image taken of a circuit board from a disassembled camera (right).

The lenses mentioned above can also be used to make a simple camera obscura using construction paper, wax paper, and tape. This project is a great way to help the students better understand how lenses work and how a camera images a scene. The students must determine the focal length of the lens and ensure that the construction paper is cut such that it can be rolled into a tube of height equal to the focal length. A circle of wax paper is traced, cut out, and taped to the end of the tube. By placing the "screen" perfectly in the focal plane of their camera obscura, the student can obtain a clear image, which is shown in Figure 3.
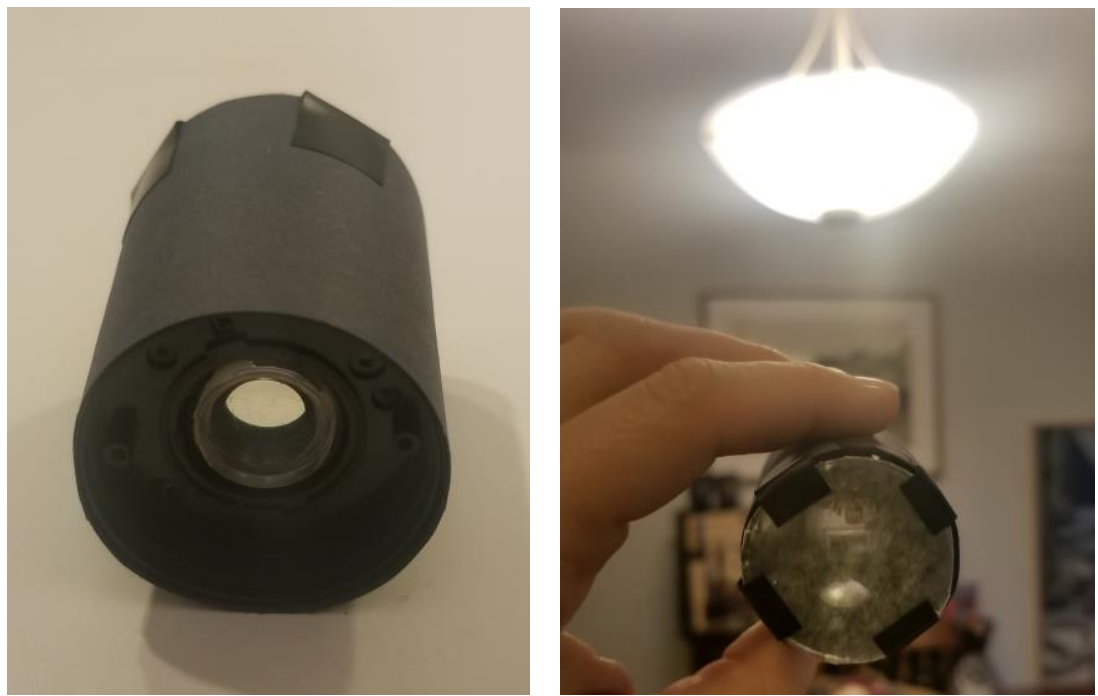

Figure 3. A simple construction paper tube camera obscura (left) with a wax paper "screen" for viewing the image (right).

We have explored the possibility of building a static electricity detector using the flash unit of the camera. Once the camera's outer housing has been removed, the flash unit is easily accessed. The flash tube assembly is detached simply by cutting the wires which connect it to the circuit board, leaving some length of wire attached to both ends of the flash tube. The wires are stripped of their insulation to expose the conductors. If one of the wires was broken off during disassembly, aluminum foil can be fixed to the side of the assembly to act as the conductor. Holding one end of the flash tube assembly by the foil or wire, one can generate static electricity by walking on carpet, rubbing a wool sweater or balloon. Now to release the charge that has built up, complete the circuit by touching the other wire connected to the flash tube to another object. The tube will briefly light up and although the flash is weak, it can be observed in a darkened room. The more charge that is built up, the brighter the flash will be. An image of the "static electricity detector" can be seen in Figure 4. 


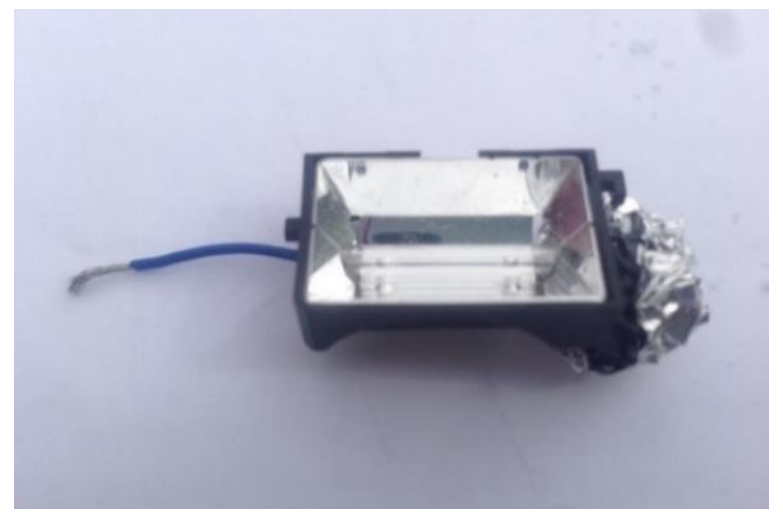

Figure 4. A static electricity detector using a camera's flash tube .

More sophisticated activities revolved around discussions of energy, motors, and electromagnets. These projects are more suited to middle school-age students and functions to teach them about different forms of energy and ways to convert or utilize energy. In addition to making vibrating junk-bots with the motors, they can be upgraded to gyrowalking-bots which use gyroscopic torque from a rotating CD to move around (Figure 5, left). They can also be used to create a simple motor-generator using a battery pack and two motors connected with a plastic straw to power an LED (Figure 5, center). Finally, for the most advance students, we worked with them to create a bipolar DC motor ${ }^{5}$ to further investigate electromagnetism (Figure 5, right). All electric connections are made by simply twisting the wires together.
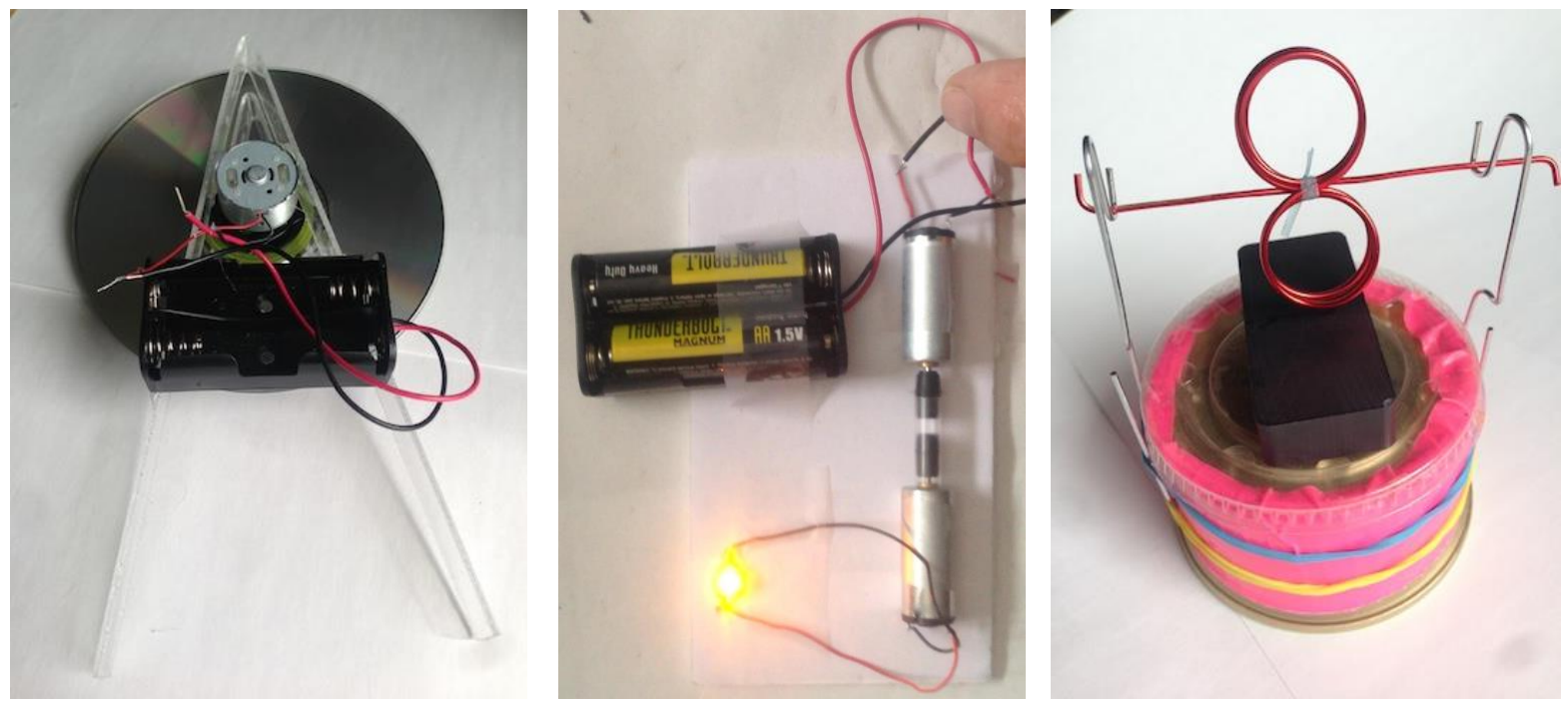

Figure 5. A gyro-walking-bot made from a re-purposed motor attached to a CD (left), a simple motor-generator unit that powers a LED (center), and a bipolar DC motor $^{5}$ demonstrating electromagnetic force (right).

\section{SAFETY CONSIDERATIONS}

The biggest safety concern in disassembling a camera is the capacitor that is used to power the flash. It produces a painful shock and must be discharged before disassembly. Moreover, it is important to recognize there are many safety concerns with all hands-on technology activities. Batteries, small parts and components are a burn, choking, or poison hazard for small children. Printed circuit boards and their components are not used due to the possible presence of hazardous materials. Springs and other small pieces can be broken off during disassembly and could cause eye damage if not wearing protective eyewear. We provided a written warning to parents regarding these and other safety concerns. 


\section{CONCLUSIONS}

We found that the disassembly of unwanted (and even broken) cameras to be an exciting and engaging activity easily accomplished by elementary-age students. Minimal preparation and no understanding of camera technology was required to initiate disassembly. Volunteers, instructors, and nontechnical parents were able to quickly learn and guide as the activity progressed. One topic for future inclusion might be the growing problem of electronic waste and e-cycling, perhaps having students investigate the composition of recyclable materials in unwanted electronics. During the disassembly, all participants appeared to be focused and engaged in the activity at hand. Boys and girls appeared to be equally adept in the disassembly process, suggesting no gender-related capability differences at this age. Students were able to work at their own pace and we could adjust intensity of the activity by distributing more or less complex cameras, tailoring lessons plans, and choosing appropriate re-purposing projects. Worksheets were helpful to building students' vocabulary and understanding of scientific concepts as well as for thinking through camera and component functionality. However, during lessons we noted that students who self-reported no interest in science tended to be less interested and attentive during this portion of the activity. Despite this, about $90 \%$ of the students said that they liked the project overall. It appears that a positive experience with science and technology at a young age could motivate students to pursue and excel in these topics in the classroom. As this project only explored the feasibility of disassembly and repurposing activities, specific classroom outcomes and effectiveness will have to be addressed in future work. A programmed disassembling of unwanted cameras appears to be an exciting and low-cost method to introduce young students to STEM fields, enabling a range of project activities and experiences through a process of inquiry. Provided that safety precautions are followed, the disassembly and re-purposing of unwanted point-and-shoot cameras produces sophisticated components, enables practical exploration and tinkering, and is a potentially useful approach in science and technology education.

We welcome all thoughts and feedback on this project - ideas for new items to disassemble, re-purposing projects, and general comments about the project. A discussion forum at the bottom of the project webpage can be used to submit feedback, http://opticsumich.com/outreach/projects/disassembly.

Acknowledgements: The authors would like to acknowledge the International Society for Optics and Photonics (SPIE) and the Optical Society (OSA) for their financial support of these activities. They would also like to acknowledge all the volunteers from the Optics Society at the University of Michigan (OSUM) and the Ann Arbor section of OSA (AAOSA). Furthermore, thank you to the volunteers of the Southside Church in Jackson and Peace Neighborhood Center in Ann Arbor that allowed us to bring this project to their afterschool programs. And a special thanks to all the participants of the project for bringing curiosity, creativity, and excitement to all the activities.

\section{REFERENCES}

[1] Sala, A. L., Dreyer, E. F., Aku-Leh, C., Jones, T., Nees, J. A., \& Smith, A., "Celebrating the International Year of Light in Michigan,” Proc. SPIE 9946, Optics Education and Outreach IV, 994602 (2016).

[2] Kennedy, E. B., Jensen, E. A., \& Verbeke, M., "Preaching to the scientifically converted: evaluating inclusivity in science festival audiences," International Journal of Science Education, Part B, 8(1), 14-21 (2018).

[3] Fantz, T. D., Siller, T. J., \& Demiranda, M. A., "Pre-collegiate factors influencing the self-efficacy of engineering students," Journal of Engineering Education, 100(3), 604-623 (2011).

[4] Ahonen, T. T., [TomiAhonen Phone Book-Statistical Review of Handset Industry], (2014).

[5] Matsumoto, Y., Sakaki, K., \& Sakaki, M., "Development of a New Method for Assembling a Bipolar DC Motor as a Teaching Material,” The Physics Teacher, 55(5), 293-297 (2017). 